\title{
Seven
}

\section{A QUANTUM WAVE MODEL OF VALUE THEORY}

\author{
Mark A. Moore
}

Mark A. Moore, a former student of Hartman's, is President of the Robert S. Hartman Institute for Formal and Applied Axiology. Identifying possible weaknesses in a moral calculus based on transfinite mathematics, in this essay he develops a different finitistic calculus based on the mathematics and the metaphysics of quantum wave mechanics. Moore develops this new finitistic quantum wave model value calculus in Sections 1-3 below; then he applies it in section 4. The first three sections were presented at the 1993 meeting of the Robert S. Hartman Institute, and section four was presented at the 1994 meeting. Moore finds many areas of substantial agreement between his quantum wave model calculus and the transfinite calculus of Hartman/Forrest; but there are significant differences also. Moore identifies at least eight serious critical flaws in the transfinite value calculus.

(1) The axiom that defines the system and the threefold hierarchy of value can differentiate eighteen binary value combinations. All eighteen are used in the Hartman Value Profile. However, the transfinite calculus can differentiate only eight distinct values. To illustrate, (using $A$ for $\aleph$, as Moore does here), $I^{I}\left(\operatorname{or} A_{1}^{A^{1}}\right)$, and $E^{l}$ (or $\left.k^{A_{1}}\right)$, and $S^{\prime}$ (or $\left.n^{A_{1}}\right)$, all yield the same resultant value of $A_{2}{ }^{1}$ This means that it is just as valuable to love a button or an idea as it is to love a person, and this is highly counterintuitive.

(2) The value distinctions between good, fair, average, poor, and bad or no good get lost when the transfinite calculus is used. All extrinsic objects and processes have the value $k$, no matter whether they are good, fair, average, poor, or no good. Transfinite algebra does not do justice to gradations of value within the three intrinsic, extrinsic, and systemic value dimensions. However, this does not happen in the quantum wave model approach.

(3) Moore is skeptical about Hartman's rank ordering of some binary value combinations, and he offers a partly new hierarchy of binary values. For example, he reverses Hartman's ranking of $S^{\prime}$ over $I^{E}$, suggesting that as he puts it, "the sacred nature of formal systems" ranks lower than "the 
positive uses of persons." Moore regards his new rank ordering as intuitively more compelling.

(4) Some of Hartman's critics like Pete Gunter ${ }^{2}$ and Robert S. Brumbaugh, ${ }^{3}$ questioned Hartman's limitation of basic values to three, intrinsic (persons), extrinsic (things), and systemic (ideas) and suggested that there might be intermediate or additional types of basic value. The need for an additional basic type of value is especially acute when it comes to non-human animals. Where neither Hartman nor Forrest can find any degree of intrinsic worth in non-human animals, and consistently classify them in the extrinsic value dimension along with rocks and doorknobs, Moore shows how to expand the initial threefold hierarchy of values into fourfold, fivefold, or however many it takes to make all the distinctions between kinds of basic values that need to be made. All animals are not equal in degree of psychic complexity, feeling, desires, volitions, cognitions, and capacity for valuation.

(5) Where Hartman was unable to explain how to compare the value of a thing's having three properties of its five propertied concept with the value of a thing's having three properties of a three propertied concept, Moore has discovered how to do it and shows us in the coming pages.

(6) Moore indicates that in fighting evil with evil (transposing transpositions), Forrest is forced to treat equals as if they were unequal, for example, ruining crops = killing insects. By contrast, the quantum wave model can show that these alleged equals are not really equal at all.

(7) Moore can get a different numerical value for all eighteen binary combinations; but the transfinite calculus gets only eight, as previously indicated. This means that the quantum wave calculus can distinguish eighteen, not just eight, distinct relations of "better than" and "worse than." It can also expand indefinitely on that. Important value distinctions or discriminations can now be made that the transfinite calculus cannot make, as Moore illustrates with many examples. Moore claims that "transfinite algebra does not provide enough resolution to deal adequately with the value landscape."

(8) In the preceding reply to Edwards, Forrest clearly shows that murder is wrong, but he does not reply adequately to the charge that the transfinite calculus implies that multiple murders are no worse than a single murder, since $A_{1}-A_{1}-A_{1}-A_{1}-A_{1}-A_{1}-A_{1}=A_{1}$. Moore emphasizes that the quantum wave approach does not yield this highly counterintuitive result.

Although this new finitistic model is in many ways superior to the transfinite model, in at least one important respect the transfinite calculus is superior. It preserves the incommensurability of the value of each person 
with the values of things and concepts. In the finitistic approach, enough money, or enough barrels of oil, eventually equal or surpass the value of a human life; but no finite extrinsic or systemic values ever equal or surpass the intrinsic worth of a single human life, according to the transfinite calculus. A richer calculus is now required that somehow combines the transfinite with the quantum wave calculus, preserving the advantages of each while avoiding the liabilities of both. Mark Moore is now working on this!

To his devoted followers, Robert Hartman's work represents a significant advance in the philosophical understanding of value. Hartman was not content to stop at philosophical understanding alone. His dream was to create a logic of value-a formal logic which not only formally differentiates types of values but also allows for calculations that combine the types of values so that the relative value of each combination can be compared. For Hartman, this enterprise represents three distinct parts, and the working out of each part exemplifies the process of creating a science.

First, there are the foundations of value. In this stage Hartman provided us with what he calls the "analysis" of value. Hartman wanted to accomplish the reduction of the understanding of value to its most simple and generic meaning. Relying heavily upon G. E. Moore, Hartman concluded that the essence of all value is the concept of "Good."

The second stage is the formal definition of the analytic simple concept "Good." This stage is called the "Axiom of Value." Hartman claimed that all true sciences have such axioms at their core. What makes this stage unique is the identification of a simple analytic concept, a concept whose meaning cannot be further analyzed, with a formal or mathematical process. In this way, the analytic concept can now be treated by the laws of mathematics. This formal treatment leads to the creation of theorems and hypotheses that can be formally derived and empirically tested.

The third stage was described by Hartman as the "Calculus of Value." Here, the formal apparatus generated by the Axiom of Value is developed. This stage contains the ranking of value types and their respective combinations.

Each of the three stages of Hartman's work find their own unique development and critique. Surely, stage one, the analysis of value, is a purely philosophical undertaking. As such, it should be critiqued as any philosophical work. This means that it can be historically placed along side 
other significant attempts to understand the nature of value. It can also be critiqued for its philosophical and argumentative soundness.

The second stage, the Axiom of Value, must be treated like any other so-called axiomatic work; namely, it must be judged for its logical consistency and usefulness in generating interesting and provocative theorems which are not only consistent with what we analytically believe to be true about value but also further our understanding and instruct us about subtleties of value that have been obscure.

Finally, the third stage of value, the Calculus, must be judged on the merits of delivery. The Calculus must provide us with a mechanism of value calculation. Here the calculations must be judged on their ability to distinguish logically what has been formally distinguished in the Axiom, and for their ability to make precise and reveal differentiations of specific values and value situations.

Importantly, a criticism of one stage is not an indictment of the entire program. Elsewhere, I endeavored to demonstrate that the third stage of Hartman's program, the Calculus of Value, is defective. ${ }^{4}$ This, however, in no way represents a rejection of stages one or two. In fact, my objections to Hartman's calculus really depend upon the acceptance of stages one and two. In my earlier critique, I pointed out that two portions of Hartman's Calculus fail the simple test of consistency.

First, the Axiom of value allows for the differentiation of eighteen binary value combinations. The calculus, however, only distinguishes eight different "numerical scores." This means, that ten of the formally distinct value combinations are really numerically indistinct. This implies that the Calculus does not do justice to the Axiom, and for me this implies that the Calculus is defective. Many axiologists are sympathetic with the argument from utility - that the Calculus is useful and therefore should not be tossed overboard. We owe Frank Forrest a great debt for the work he has done to codify value calculations. However, the simple fact remains that the Calculus does not do justice to either the Analytic or the Axiomatic stages of Hartman's work, and this must be rectified.

Second, the Axiom requires that we employ a multi-valued logic in the Calculus. Valuations, according to the Axiom, are gradations of value. Values are sets which are fulfilled in a range of ways going from no-good, to poor, to average, to fair, to good. However, Hartman never delivered a calculus that actually does this with logical consistency. When he calculated the relative value of how an extrinsic value may be evaluated either systemically, extrinsically, or intrinsically he only employed the value mode of systemic value. There is no calculus based on the partial 
fulfillment of extrinsic value. From the view of the Calculus, the extrinsic evaluation of any extrinsic value is the same, but we know from the Axiom and other parts of the Calculus that this is not logically consistent.

I am critical of Hartman's Calculus of Value, and I believe that proper respect for science in general, and Hartman's lifelong work in particular, requires that all defective aspects be openly challenged and if possible replaced. This is science and not religion. Dogma within a science is a value transposition, and ultimately no good comes of it.

Having said this, there is still a point to be made about being only negative. It is easier to criticize than to fix. I am sensitive to this; indeed, science does not stride forward merely by finding error, but in the discovery of new frameworks. This paper attempts to provide a constructive alternative to Hartman's Calculus of Value. As such, it must be evaluated by two important criteria: First, is this alternative genuinely consistent with Hartman's Axiom of Value. Second, is the calculus presented here logically consistent, interesting, and fruitful in its development and applications. I invite your healthy suspicions.

\section{A Review of Certain Aspects of Quantum Logic}

Quantum mechanics is one of the great achievements of human intellect. Viewed simply, it is a part of physics. More specifically, it is the physics of the atom. Quantum mechanics may also be seen as a mathematical and logical system. This aspect was developed especially by John Von Neumann. To consider quantum theory only in its applications for physics and mathematics (as extraordinary as they are) would be an injustice, however, for it represents a new way of thinking about nature, about logic, and about process.

Simply put, quantum mechanics challenges our notions of what it means to be located in space, what it means to be a member of a class or an element in a set, and what is means to endure through time. In this paper, I will focus on these larger, more philosophical aspects of quantum theory, and more formal aspects are only slightly discussed.

\section{A. Wave vs. Particle}

To grasp the importance of quantum theory, several critical aspects must be understood. These aspects center on the basic dualism of quantum theory, the duality of wave and particle in the interpretation of nature.

At the end of the nineteenth century, physicists were content to think of 
nature as composed of two parts: matter and fields. Drop an apple from a tree. The apple is matter; and it falls due to its attraction to a larger piece of matter, Earth. Connecting the apple in the tree and Earth is a field, the gravitational field. The complexity of the atomic world was yet to be discovered, and many physical fields and forces were still unknown. Physicists were content to treat matter and fields as separate entities. This began to change, first with the work of Clerk Maxwell, and later with Albert Einstein's demonstration that classical matter and fields are convertible to each other, and with Max Planck's proof that the interconnectedness of field and matter is a fundamental principle of the world of the atom, not merely a theorem of classical physics.

Planck's initial work centered on the question of why hot things change color. That black body matter glows when heated was already known. Steelmakers had known for generations that iron turns cherry red at about 1300 degrees, and this was a good way of knowing the temperature of a furnace. But why does this change occur? Planck discovered that atoms glow or give off color due to their vibrations. If one adds heat, vibrations increase in frequency, and this accounts for the change in color. There is, then, a direct correlation between the frequency of the atom's vibration, the amount of energy applied to the atom, and the color or frequency of the light emitted by the atom. All of this seems reasonable, but Planck also discovered that changes of the frequency of light emitted by the atom do not proceed in a linear fashion with increased energy input. Rather, there is a step function. Changes in output (light) occur only after sufficient additional energy has been absorbed. This step function, these packets of released energy, Planck called "quanta;" and the constant he discovered is called "Planck's Constant."

The plot thickened when physicists turned to the nature of light. Work done by Christian Huygens and Sir Isaac Newton established that light is a wave (and thus a field). However, Arthur Compton demonstrated that light behaves like a particle. So, which is it? Is light a wave or a particle? While this controversy was boiling, Louis De Broglie submitted a doctoral thesis proposing that all particles of matter are associated with particular waves. Just as light waves have the properties of particles, particles have the properties of waves. Waves and matter are somehow interconnected. This duality was formally presented by Werner Heisenberg in 1925. Therefore, quantum theory is about the interchangeability of particles and waves; and it has two versions-a wave version developed first by Erwin Schrödinger, and a particle version developed by Werner Heisenberg.

It may sound as if the problem was then solved: quantum theory supplies 
the formal framework for the transition of wave into particle and vice-versa. But it is not so simple. In fact, the duality of the two states (wave and particle), and the contradictory ways in which each state behaves, are not reconciled. The problem is not solved, only presented in a more precise way. The problem is that matter can be validly seen as a wave or as a particle; but particles are very different from waves. It would be fine if we could show that matter is at one point behaving like a particle, and at different time it has changed its behavior and begins behaving like a wave; but this is not what happens. Matter behaves equally like a particle and a wave at the same time, and this challenges our common sense view of reality.

1. As a particle, matter is simply located at a specific point in space. As a wave, matter is located generally along the entire volume of space the wave occupies.

2. As a particle, matter interacts with other particles in a Newtonian fashion (rather like billiard balls colliding). As a wave, matter interacts by phase coherence.

3. As a particle, matter and energy are conserved. When two particles of matter collide the energy released is equal to the energy lost in the two respective particles. When waves interact, the energy of the combined wave is equal to the square of the wave energies. An energy increase and deficit is created.

4. As a particle, matter changes direction and loses energy after collision. As a wave, matter returns to its original amplitude and energy after interference.

These are serious conflicts. They have not been reconciled by quantum theory today. To make matters worse, we are not free to accept one model or the other. We cannot be particle or wave theorists and let that be the end of it. The history of quantum theory is filled with attempts to explain away the conflict. In the Copenhagen Thesis, the "reality" of matter outside some experiment is not a meaningful question. This implies that measurement somehow interacts with matter, altering its natural condition. Measurement, then, is seen as a type of interference. However, in 1964 John Bell showed that this and similar ways around the problem fail. Bell demonstrated, in what is now called Bell's Theorem, that without faster-than-light connections (which would violate Einstein's most basic principle of general relativity) a theory of matter based on a particle model cannot explain the facts as we know them. It is not a matter of choosing equally satisfying theoretical models. Neither side, by itself, can explain all the facts. We seem to be left with what Von Neumann calls a "miracle." 
Understanding this constitutes one of the great achievements of human intellectual history.

\section{B. The Wave Nature of the Electron}

We have a rather good understanding of how particles behave, as explained by the mechanics of Newton. While there is subtlety in Newton's mechanics, there are no big surprises. What is surprising is how matter behaves in its wave form at the quantum level. In our everyday world of classical scale, the world we inhabit, we are familiar with the actions of matter on matter. There is great similarity between this world and the small atomic world when we think of matter as particle. However, as a wave, matter behaves very differently. Since we are less familiar with wave mechanics in general, and quantum waves in particular, I will comment on the nature of waves, and on probabilities and possibilities. Later I will show how important these topics are to our understanding of intensions or meanings of concepts. First we must turn our attention to the wave nature of matter.

The wave nature of the electron is best demonstrated by examining what happens when an electron is fired through a single hole, and then through multiple holes. Today we are all familiar with the firing of electrons onto a phosphor screen (a television). If the beam of electrons is focused through a single hole, then we expect to see a single bright spot on the screen. If the intensity of the beam is increased, the spot brightens. So far, so good. If the diameter of the hole is decreased then the diameter of the spot likewise decreases. This is as expected. However, at a certain point, a strange thing begins to happen. Instead of getting smaller, the spot on the screen begins to expand. Not only does it expand, but it does so in circles of bright and dark areas which resemble a bull's eye target used by an archer.

This pattern, called the Airy Pattern, was discovered by George Airy in 1835 by looking at the effects of passing any type of wave through a hole or iris. Airy's pattern applies equally to waves of water, light, or sound. Airy noticed that the angular diameter of the bull's eye is:

\section{$70 *$ (wave length/the diameter of the iris).}

It has been suggested that the reason a beam of electrons forms the Airy Pattern is not because electrons are waves, but because a stream of electrons, trying to get through the hole, simply form a wave from their 
collective flow. This, however, is not the case. If flow of electrons is slowed down by firing one each minute, the Airy Pattern will still be found. The wave nature is a part of the electron's intrinsic nature, and that's all there is to it.

The same pattern appears when photons of light are passed through small holes. In the famous two-slit experiment, photons of light behave exactly like waves as they pass through both slits. With both slits open, the same wavy pattern arises. Even more interesting, with both slits open and twice the light reaching the screen, the brightest areas are not twice as bright, but four times as bright as with a single slit open. In other words, when waves cohere, the effect is double the expected; and when waves interfere, the effect is complete wave cancellation, or darkness. This curious phenomenon can be explained, but to comprehend it we must explore the nature of wave coherence and interference.

\section{Wave Mechanics}

To understand how waves behave, we need to know how they are measured. This is done in three ways. First, wave amplitude, the height of the wave, is determined. Second, frequency of period, the time it takes the wave to complete a cycle going from the top of the wave to the bottom and back to the top, is calculated. Third, the energy is gauged. The energy is also equal to the amplitude squared for any portion of the wave. In quantum theory, waves actually do not have energy but probability, which is equal to amplitude squared. The higher the amplitude, the greater the probability of a given state's occurring. For quantum theory, wave amplitude is a distribution of the probabilities of the possible states of a system.

To understand what happens when two waves meet, we need only compare the phases of the respective waves. If waves are perfectly in phase, then the peaks and troughs are in complete synchronization. This is called coherence. Any deviation from perfect coherence is called interference. Interference can be partial or total, where the peaks line up with troughs, and vice-versa. In this case we have complete wave destruction.

When waves meet, their amplitudes add. If they are in phase, then the resulting wave is the addition of both amplitudes. If they are completely out of phase, then one amplitude is subtracted from the other. All degrees in between are the result of the degree of phase. This process, called "superposition," works on a linear scale until very large amplitudes are 
combined, where distortion or non-linearity can set in. It is thought, however, that for quantum waves, non-linearity never sets in. After meeting, two waves may again separate. What is remarkable is that after separation, the two waves resume the original amplitude they possessed prior to meeting. It is as though nothing happened.

As mentioned earlier, a wave's energy (or probability) is its amplitude squared. This means that a sea wave with an amplitude of four feet has four times the (destructive) energy as a wave with an amplitude of two feet. Imagine the destructive power of a two hundred-foot wave! (One occurred in Valdez, Alaska in 1964). For quantum waves, probability is the square of the amplitude. If we imagine one quantum wave with an amplitude of 2 and another with an amplitude of 4 , the wave with amplitude of 4 is not twice as likely to occur, but four times more likely to occur.

In the early 1800's, the French mathematician Joseph Fourier discovered that any wave can be uniquely expressed as a combination of sine waves. Fourier's analysis applies to musical instruments, for example. When two different instruments play the same note, their waves are different. These differences give a unique sound to each instrument. This explains why electronic instruments such as the Moog synthesizer can duplicate the sounds of many different instruments by duplicating the unique Fourier signatures for each instrument. Fourier's discovery is even more general than he envisioned. Not only can sound waves be analyzed as a composite of sine waves, but this magical analysis can be performed by using wave groups other than sine waves. There is no natural way to take a wave apart. For every type of wave, there is a way to analyze it.

\section{Types of Waves}

In general, there are three types of waves: impulse waves, sine waves, and spherical waves. Impulse waves are sharp spikes. They are infinitely narrow and one-dimensional. One impulse wave differs from another only in its location. Sine waves have a characteristic shape; and two dimensions are required to describe them properly. Finally, spherical waves consist of the vibrations of hollow spheres and exist in three dimensions.

The analysis of a wave by wave type is a complex mathematical process that is best solved by today's high speed computers. The result of wave analysis in music is the compact disk or synthesizer. (Compact disks and synthesizers use impulse waves to create the various sine waves for each instrument and note. This can also be done by analogue.) However, the number of iterations necessary for the analysis of a given wave will depend 
upon the "familiarity" of the wave with the wave form used for the analysis. This "kinship" relation of wave to analysis is very valuable. This is similar to a prism through which light is passed. The complexity of the spectrum as it leaves the prism is a measure of the similarity of the prism to the light wave. If there is no change in the wave, then the prism and the wave are in complete one to one mapping. Max similarity is called "kin prism" and max dissimilarity is called "conjugate prism." The measure of dissimilarity is the bandwidth of the spectrum. The larger the bandwidth, the greater the conjugate wave, the greater the dissimilarity.

\section{The Relation of Quantum Theory to Value Theory}

What, it may be asked, does all of this have to do with value theory? Value theory is about what people desire; quantum theory concerns the atomic world. The answer is that quantum theory involves a multi-valued logic that describes the probabilistic behavior of particles of matter and the combinatorial aspects of waves of matter. Waves of matter must be thought of as the total possibilities of action, and quantum theory provides the logic for how these total possibilities combine. It may be objected that the quantum world is small, and its effects are not noticed in the world we know. This is only partially true. First, the proxy waves of photons of light from distant stars can be several meters wide, and thus they are not only creatures of the atomic world. Second, as Roger Penrose points out, quantum effects may be sufficiently robust to be experienced by the human brain. $^{5}$ To be serious about this comparison, we must do more than speculate. A direct comparison between value theory and quantum theory is necessary. In the following discussion, I propose to make just this comparison.

\section{A. Wave Families: Types of Concepts}

For Robert S. Hartman, there are three types of concepts: Formal, Analytic, and Singular. Each type represents a value: Systemic, Extrinsic, and Intrinsic. Each type is differentiated by the way in which the intensions and extensions are related. For formal concepts, intensions and extensions vary directly, and each is a formal construct. In analytic concepts, intensions and extensions vary inversely. The predicates of analytic intensions consist of other predicates, and the extensions of analytic concepts are properties of things. In singular concepts, the intension and the extension are unified into a one-to-one mapping, a topology. This three- 
fold distinction is very similar to the different wave families: impulse, sine, and spherical. Impulse waves are like formal concepts in that they are onedimensional; only their position differentiates one from another. Sine waves are like analytic intensions in that they are two-dimensional, (and time is a third dimension). Finally, spherical waves are like singular intensions; they are by nature continuous in a fashion that is suggestive of intrinsic value.

\section{B. Particles and Waves: Intensions and Extensions}

For Hartman, the foundation of all value lies in the understanding of the nature of concepts. Concepts are composed of two aspects, intensions or meanings and extensions or properties to which meanings refer. Meanings consist of predicates, and things consist of properties. Concepts involve both.

This distinction resembles the difference between the wave and particle nature of quanta. A wave is similar to an intension. A quantum wave is the possibility that a certain physical state will occur. Possibility squared is probability. For Hartman's theory, the intension represents the full range of possibility of the extension. The extension is some sub-set of properties named by a subset of predicates in the intension. The total value of these extensional sub-sets of properties that define extension is equal to nothing less than the total meaning of the concept. In both quantum theory and value theory, the intensional wave represents possibility and the extension represents probability. In fact, total meaning (possibility) is equal to the square of the probability. Probability is determined by the amplitude of the wave for any specification of properties. Total meaning for the intension is the square of the number of properties.

\section{Wave Interference and Value}

Intensional analysis is wave analysis. Since the intension is the measure of value, we ought to be able to apply the logic of wave interference to intensions. In fact, we can. First, the way values combine or blend is similar to how waves combine. Wave combinations are measured by amplitude and phase. If waves are out of phase, then the combination is destructive; if they are in phase, then the combination is constructive. Degrees of phase control the resulting combinatorial possibilities.

Extensional analysis, on the other hand, is like particle analysis. Properties behave in a Newtonian fashion. Their combinations are probabilistic. 
This is very much like value composition and transposition. The difference is that for Hartman, values are either completely in phase or completely out of phase. Although he speaks of partial concept fulfillment in extrinsic value, the combinations of value types are not partial; they are either completely in phase or out of phase. The "quanta" of value are unfortunately either "on or off," "plus or minus." Like waves, intensions have been combined and uncombined without destruction. This is not true for extensions. Once the two automobiles collide, the scars remain. Humpty Dumpty cannot be put together again.

\section{Heisenberg's Uncertainty Principle and Analytic Concepts}

A cornerstone of Quantum theory is the Uncertainty Principle. Simply stated, knowledge about a quantum event is possible but limited. As we increase knowledge in one area, we lose knowledge in others. The total we can know at a given time is limited and relational. Thus, knowing more about one area will limit what we can know about another.

But of what are we uncertain? In The Emperor's New Mind, Roger Penrose points out that when we are considering merely the possibility of quantum activity, we are never uncertain. Uncertainty creeps in only when we try to determine probability. Remember, probability is the amplitude of the wave squared; it is possibility squared. (We can measure the amplitude at any point along the curve, not only at the maximum.) In the value sense, this is the level of total meaning or value. The Uncertainty Principle is then a Principle of Total Value.

This is very much like the relation of intension to extension of analytic concepts. The greater the knowledge of the extension, the less the knowledge of the intension. (This may not be true of singular concepts, but we cannot speak strictly of "knowledge" when we encounter "singularities.") If a concept has three (expositional) properties, then we know that there is one way to have none of these properties (and be no-good), three ways to have one property (and be poor), three ways to have two properties (and be fair), and one way to have all three properties (and be good). Nothing is uncertain. However, since intensions and extensions vary inversely, the more we know with increased levels of specification, the less is known about higher levels of abstraction; thus, probability decreases. We cannot increase the level of specification and at the same time increase probability. 


\section{E. Conclusions}

Many aspects of quantum theory are similar to value theory. Upon reflection, however, this should not surprise us. Meaning, for Hartman, is a wave. Hartman does not develop this area of value theory, but it is subject to wave analysis. Like quantum theory, value theory requires that meanings be either in phase or out of phase; either there is composition or transposition. This alone should prompt us to look to wave mechanics to understand values better. In the final section of this paper, I will actually use principles of wave mechanics to calculate values.

\section{Quantum Wave Model for Value Combinations}

Quantum mechanics is a theory about the dual nature of matter. Matter is a simply located particle with a certain probability, and it is also a possibility or meaning wave. According to Von Neumann, this dual nature requires consciousness. From my perspective, it is the essence of value. The quantum proxy wave, the possibility of action, is the intension of a concept against which the extension, the particle nature of matter, is measured. These are value measurements, and they can be compared by a method of computing quantum wave vectors.

A vector is a way of calculating amplitudes of the wave. The longer the vector, the greater the value. But quantum vectors are not ordinary. Waves can be in phase or out of phase. The dark areas in wave interference charts are areas out of phase; the most intense areas are areas in phase. We can apply these principles directly to value and valuation.

Following Roger Penrose, the formula we shall use is similar to the calculation of a quantum vector. In general, a vector is an outcome of two input variables; it summarizes the result. Typically, this is done by allowing the two inputs to be sides of a right triangle, and the vector is the hypotenuse. The Pythagorean Theorem is the standard method. However, since quantum vectors are waves that can either be in phase or out of phase, the formula is a little more complex. The actual formula is:

$$
a^{2}+b^{2}=c^{2}+2 *(a * b * \operatorname{cosine~theta~})
$$

where theta is the angle of the vector. The cosine is derived by dividing the adjacent line segment by the hypotenuse, which in this case is the valuation of a value. 


\section{BASE}

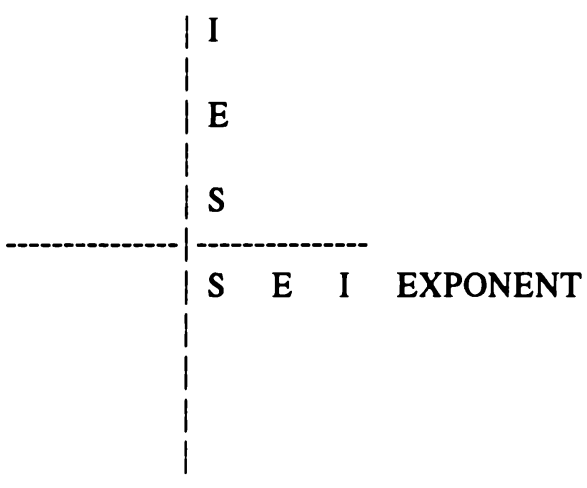

This additional correction term accounts for the interference lines of bright to dark in the wave combinations of quantum mechanics. If theta = 0 degrees, then the cosine $=1$; the two waves are totally in phase; and the waves combine geometrically. If theta $=90$ degrees, then the cosine $=0$; and the waves combine arithmetically. If theta $=180$ degrees, then the cosine $=-1$, and the waves cancel each other. All cosines in between give varying degrees of wave amplification and destruction.

\section{A. Binary and Tertiary Value Combinations}

For us, the vector will summarize the axiological process of binary and tertiary compositions and transpositions of value. In the act of valuation, a base value is valuated. A vector can be calculated to summarize the overall resulting value. In tertiary combinations, the vector of the binary valuation is itself valuated; and a three-dimensional vector is created. There is, however, one important difference with quantum theory. In quantum mechanics, wave interference is a cancellation; but in formal axiology it is a transposition. Therefore, the dark areas in quantum mechanics are areas of transposition in axiology. Transpositional vectors measure the intensity of the darkness, just as compositions measure the intensity of the brightness.

The next step is to assign an amplitude number for each of the types of values. There are three kinds of value, and each needs a number. For Hartman, these numbers are finite, infinite, and non-denumerably infinite. In my view, this is where Hartman gets into trouble. I choose to employ a very simple convention. Let the lowest value be represented by a single 
unit of value, the next value by two units, and the highest value by three units. Thus,

$$
\begin{aligned}
& \text { systemic value }=1 \text { unit; } \\
& \text { extrinsic value }=2 \text { units; and } \\
& \text { intrinsic value }=3 \text { units. }
\end{aligned}
$$

There are, then, 6 total value units since the sum of the above units is six. Systemic value is $1 / 6(.167)$; extrinsic value is $2 / 6$ (.333); and intrinsic value is $3 / 6(.50)$. These numbers add to 1.0 . Each represent base values and the exponents of the process of valuation.

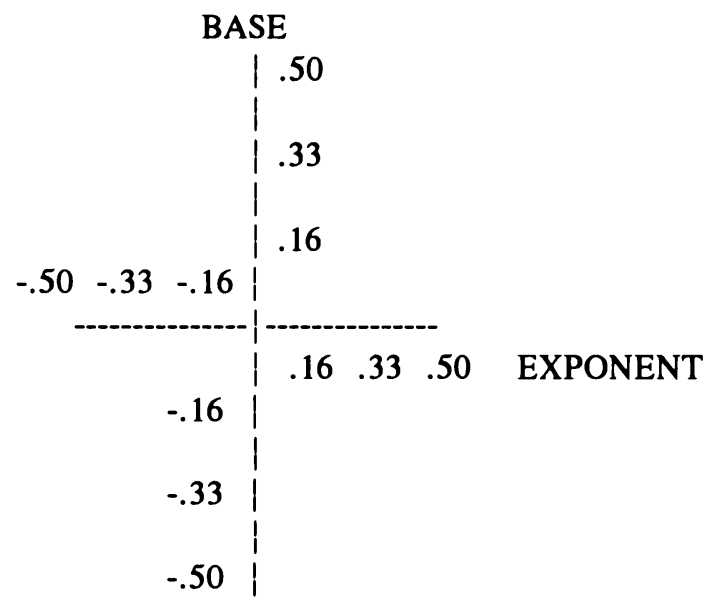

Using these units as input, we get the following unique ranking for the eighteen binary value combinations: 
BINARY VALUE COMBINATIONS

\begin{tabular}{|c|c|c|c|c|c|}
\hline $\begin{array}{l}\text { HART } \\
\text { RANK }\end{array}$ & $\begin{array}{l}\text { LAN } \\
\text { BASE }\end{array}$ & AL\#1 & VECTOR & VALUATION \# 1 & BASE VALUE \\
\hline 1 & I & I & 0.9239 & The Sacred Nature of & Persons \\
\hline 2 & $\mathrm{E}$ & I & 0.7965 & The Sacred Nature of & Animate and Inanimate Things \\
\hline 4 & I & $\mathrm{E}$ & 0.7353 & The Positive Uses of & Persons \\
\hline 3 & $S$ & I & 0.6542 & The Sacred Nature of & Formal Systems \\
\hline 6 & $\mathrm{E}$ & $\mathrm{E}$ & 0.6097 & The Positive Uses of & Animate and Inanimate Things \\
\hline 5 & I & $S$ & 0.5695 & The Rational Views of & Persons \\
\hline 7 & $\mathbf{S}$ & $\mathrm{E}$ & 0.4790 & The Positive Uses of & Formal Systems \\
\hline 8 & E & $\mathbf{S}$ & 0.4249 & Rational Views of & Animate and Inanimate Things \\
\hline 9 & $S$ & $\mathbf{S}$ & 0.2957 & Rational Views of & Formal Systems \\
\hline 10 & $\mathbf{S}$ & $-S$ & -0.2957 & Irrational Views of & Formal Systems \\
\hline 11 & $\mathrm{E}$ & $-S$ & -0.4249 & Irrational Views of & Animate and Inanimate Things \\
\hline 12 & S & $-E$ & -0.4790 & Negative Uses of & Formal Systems \\
\hline 14 & I & $-S$ & -0.5695 & Irrational Views of & Persons \\
\hline 13 & $\mathrm{E}$ & $-E$ & -0.6097 & Negative Uses of & Animate and Inanimate Things \\
\hline 16 & $\mathbf{S}$ & $-\mathrm{I}$ & -0.6542 & The Total Destruction of & Formal Systems \\
\hline 15 & I & $-E$ & -0.7353 & The Negative Uses of & Persons \\
\hline 17 & $\mathrm{E}$ & $-\mathrm{I}$ & -0.7965 & The Total Destruction of & Animate and Inanimate Things \\
\hline 18 & I & $-\mathrm{I}$ & -0.9239 & The Total Destruction of & Persons \\
\hline
\end{tabular}


Vector length is an indication of value. Positive vectors are compositions and negative vectors are transpositions. There is a symmetry between positive and negative vector lengths. The worst transposition is equal and opposite to the best composition. These eighteen types represent the basic model for binary valuation. I indicate the base values as $I, E$, and $S$ respectively. As examples of the three base value types, I choose the following: Intrinsic Value $=$ Persons; Extrinsic Value $=$ Animals and Inanimate Things; and Systemic Value $=$ Formal Systems. The valuations (Val. \# 1) of these base values are indicated by either a positive or negative I, E, or S. As examples of the positive valuation of the base values, I choose the following: Intrinsic Valuation = Sacred Nature; Extrinsic Valuation = Uses of; and Systemic Valuation = Rational Views. As examples of the disvaluation of the base values, I choose: Intrinsic Disvaluation $=$ Total Destruction; Extrinsic Disvaluation $=$ Negative Uses; and Systemic Disvaluation = Irrational Views. The Hartman ranking is also included. Notice that the Hartman ranking differs from mine in several places. For example, Hartman ranks "The Sacred Nature of Formal Systems" higher than "The Positive Uses of Persons." I reverse this order. Within transpositions, my method ranks "The Negative Uses of Persons" as worse than "The Total Destruction of Formal Systems." Hartman reverses this order. It is interesting to ponder these differences.

In Hartman's system, there are only three types of base values and three types of valuations of these values. This leaves some value theorists uncomfortable about having to group animate and inanimate objects together into one category. The quantum model, on the contrary, offers the capacity to expand the base values at will. The following two tables represent two expansions of base values. The first table separates the animate from the inanimate and thereby creates four base values: Persons (I1), Animate Things (I2), Inanimate Things (E), and Formal Systems (S). As before, the four base values are given unit values and then normalized. These values are:
$\mathrm{S}=1$ Unit or .10 ;
$\mathrm{E}=2$ Units or .20;
$\mathrm{I} 2=3$ Units or .30 ; and
I1 $=4$ Units or .40 .

Here we have 10 total value units. The vector ranks are: 
BINARY VALUE COMBINATIONS

(With Animate and Inanimate Things Distinguished)

\begin{tabular}{|c|c|c|c|c|c|}
\hline $\begin{array}{l}\text { Hartman } \\
\text { Rank } \\
\end{array}$ & Base & Val\#1 & Vector & Valuation \# 1 & Base \\
\hline 1 & II & I & 0.8500 & The Sacred Nature of & Persons \\
\hline 2 & $\mathrm{I} 2$ & I & 0.7728 & The Sacred Nature of & Animate Things \\
\hline 2 & $\mathrm{E}$ & I & 0.6896 & The Sacred Nature of & Inanimate Things \\
\hline 4 & I1 & $E$ & 0.6609 & The Positive Use of & Persons \\
\hline 3 & $S$ & I & 0.5984 & The Sacred Nature of & Formal Systems \\
\hline 6 & $\mathrm{I} 2$ & $\mathrm{E}$ & 0.5877 & The Positive Use of & Animate Things \\
\hline 6 & $E$ & $E$ & 0.5116 & The Positive Use of & Inanimate Things \\
\hline 5 & I1 & $\mathrm{S}$ & 0.4828 & Rational Views of & Persons \\
\hline 7 & $\mathbf{S}$ & $\mathrm{E}$ & 0.4266 & The Positive Use of & Formal Systems \\
\hline 8 & $\mathrm{I} 2$ & $S$ & 0.4010 & Rational Views of & Animate Things \\
\hline 8 & $E$ & $S$ & 0.3250 & Rational Views of & Inanimate Things \\
\hline 9 & $\mathbf{S}$ & $\mathbf{S}$ & 0.2504 & Rational Views of & Formal Systems \\
\hline 10 & $\mathbf{S}$ & $-S$ & -0.2504 & Irrational Views of & Formal Systems \\
\hline 11 & $\mathrm{E}$ & $-S$ & -0.3250 & Irrational Views of & Inanimate Things \\
\hline 11 & $\mathrm{I} 2$ & $-S$ & -0.4010 & Irrational Views of & Animate Things \\
\hline 12 & $\mathbf{S}$ & $-E$ & -0.4266 & The Negative Uses of & Formal Systems \\
\hline 12 & I1 & $-S$ & -0.4828 & Irrational Views of & Persons \\
\hline 13 & $\mathrm{E}$ & $-E$ & -0.5116 & The Negative Use of & Inanimate Things \\
\hline 13 & $\mathrm{I} 2$ & $-E$ & -0.5877 & The Negative Use of & Animate Things \\
\hline 16 & $S$ & $-I$ & -0.5984 & The Total Destructions of & Formal Systems \\
\hline 15 & I1 & $-E$ & -0.6609 & The Negative Use of & Persons \\
\hline 17 & $\mathrm{E}$ & $-I$ & -0.6896 & The Total Destruction of & Inanimate Things \\
\hline 17 & I2 & $-I$ & -0.7728 & The Total Destructions of & Animate Things \\
\hline 18 & I1 & $-\mathrm{I}$ & -0.8500 & The Total Destruction of & Persons \\
\hline
\end{tabular}


To take this analysis further, we may wish to distinguish between Plants and Animals within the category of "Animate Things" (I1). We represent this as Animals (I2), Plants (E1), and Inanimate Things (E2). Above we included animate things as (I2) intrinsic value. We shall continue this practice here. None of this would change the ordinal arrangement of the value combinations measured by the vector; only what we call an item would change. By our process, these five categories are given a value unit and then normalized.

$$
\begin{aligned}
& S=1 \text { Unit or } .066 ; \\
& \text { E2 }=2 \text { Units or } .133 ; \\
& \text { E1 }=3 \text { Units or } .200 ; \\
& I 2=4 \text { Units or } .266 ; \text { and } \\
& I 1=5 \text { Units or } .333
\end{aligned}
$$

Now there are 15 total value units which yield new rankings. These rankings are found in the immediately following table on page 191 .

Next, we can generate the tertiary relations, as illustrated in the tables on pages 194-197. This is based on using the binary vectors as a base; then each of these vectors is valued by the three compositions and the three transpositions. These vectors are three-dimensional and create a unique ranking for all 108 tertiary combinations. Notice that I have consistently used the same descriptions to exemplify each of the 108 types. Notice also that the vectors come in pairs of equal length. For example, in the first two rows, "I I I" equals vector length of 1.2423 as does "I -I -I." This means that the intrinsic disvaluation of an intrinsic disvaluation is as valuable as the intrinsic valuation of an intrinsic valuation. This implies, for example, that the intrinsic commitment to the elimination of killing persons is as valuable as the intrinsic commitment to great love of persons. However, these two vectors are not identical; while they are the same length, they do not occupy the same space. In fact, they point in very different directions. I have indicated this difference by the category called "QUAD" for quadrant. On the chart on page 193, these vectors are clearly distinguishable. The disvaluation of transpositions is a positive value. These are found in Quadrant \# IV. Valuations of compositions, which are also positive, are found in Quadrant \# I. Disvaluations of compositions are found in Quadrant \# II, and valuations of transpositions are found in Quadrant \# III. Even if we were to include more complex axiological constructions, they would all be distinct vector lengths in distinct (many-dimensional) sectors. In this representation, I do not include separations of Extrinsic Value into categories of Inanimate, Plants or Animals. However, this could be done. 


\section{BINARY VALUE COMBINATIONS}

\section{HARTMAN}

(With Animals, Plants, and Inanimate Things Distinguished)

\begin{tabular}{|c|c|c|c|c|c|}
\hline RANK & BASE & VAL\#1 & VECTOR & VALUATION \# 1 & BASE \\
\hline 1 & $\mathrm{I1}$ & I & 0.7965 & The Sacred Nature of & Persons \\
\hline 2 & $\mathrm{I} 2$ & I & 0.7405 & The Sacred Nature of & Animals \\
\hline 2 & E1 & I & 0.6896 & The Sacred Nature of & Plants \\
\hline 2 & E2 & I & 0.6266 & The Sacred Nature of & Inanimate Things \\
\hline 4 & I1 & $\mathrm{E}$ & 0.6097 & The Positive Use of & Persons \\
\hline 3 & $\mathbf{S}$ & I & 0.5596 & The Sacred Nature of & Formal Systems \\
\hline 6 & 12 & $\mathrm{E}$ & 0.5580 & The Positive Uses of & Animals \\
\hline 6 & E1 & $\mathrm{E}$ & 0.5116 & The Positive Uses of & Plants \\
\hline 6 & E2 & $\mathrm{E}$ & 0.4534 & The Positive Uses of & Inanimate Things \\
\hline 5 & I1 & $\mathbf{S}$ & 0.4249 & Rational Views of & Persons \\
\hline 7 & $\mathbf{S}$ & $E$ & 0.3892 & The Positive Uses of & Formal Systems \\
\hline 8 & I2 & $\mathbf{S}$ & 0.3699 & Rational Views of & Animals \\
\hline 8 & E1 & $\mathbf{S}$ & 0.3250 & Rational Views of & Plants \\
\hline 8 & E2 & $\mathbf{S}$ & 0.2735 & Rational Views of & Inanimate Things \\
\hline 9 & $\mathbf{S}$ & $\mathbf{S}$ & 0.2172 & Rational Views of & Formal Systems \\
\hline 10 & $\mathbf{S}$ & $-\mathbf{S}$ & -0.2172 & Irrational Views of & Formal Systems \\
\hline 11 & E2 & $-S$ & -0.2735 & Irrational Views of & Inanimate Things \\
\hline 11 & E1 & $-\mathbf{S}$ & -0.3250 & Irrational Views of & Plants \\
\hline 11 & $\mathrm{I} 2$ & $-\mathbf{S}$ & -0.3699 & Irrational Views of & Animals \\
\hline 12 & $\mathbf{S}$ & $-E$ & -0.3892 & The Negative Uses of & Formal Systems \\
\hline 14 & I1 & $-S$ & -0.4249 & Irrational Views of & Persons \\
\hline
\end{tabular}


HARTMAN

\begin{tabular}{llllll} 
RANK & BASE & VAL\#1 & VECTOR & VALUATION \# 1 & BASE \\
\hline 13 & E2 & - E & -0.4534 & The Negative Uses of & Inanimate Things \\
13 & E1 & - E & -0.5116 & The Negative Uses of & Plants \\
13 & I2 & - E & -0.5580 & The Negative Uses of & Animals \\
16 & S & - I & -0.5596 & The Total Destruction of & Formal Systems \\
15 & I1 & - E & -0.6097 & The Negative Uses of & Persons \\
17 & E2 & - I & -0.6266 & The Total Destruction of & Inanimate Things \\
17 & E1 & - I & -0.6896 & The Total Destruction of & Plants \\
17 & I2 & - I & -0.7403 & The Total Destruction of & Animals \\
18 & I1 & $-I$ & -0.7965 & The Total Destruction of & Persons
\end{tabular}




\section{TERTIARY VECTORS}

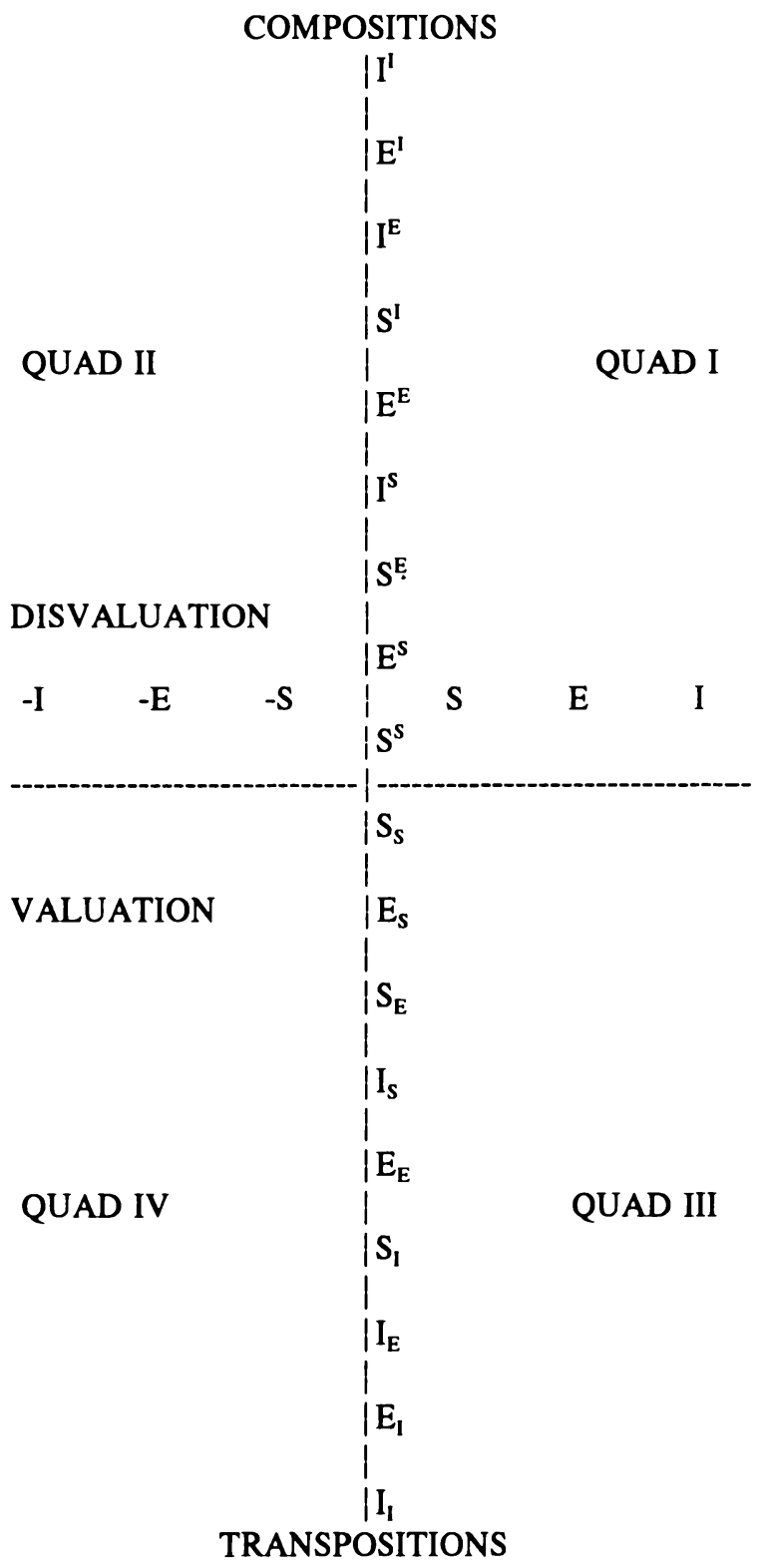


TERTIARY VALUE COMBINATIONS

VAL VAL

\begin{tabular}{|c|c|c|c|c|c|c|c|}
\hline BASE & $\# 1$ & \#2 & VECTOR & OUAD & VALUATION \# 2 & VALUATION \# 1 & BASE \\
\hline I & I & I & 1.2423 & I & Total Commitment to & The Sacred Nature of & Persons \\
\hline I & $-\mathbf{I}$ & $-\mathbf{I}$ & 1.2423 & IV & Total Destruction of & The Evil Nature of & Persons \\
\hline $\mathbf{E}$ & $\mathbf{I}$ & I & 1.1436 & I & Total Commitment to & The Sacred Nature of & Animate and Inanimate Things \\
\hline $\mathbf{E}$ & $-\mathbf{I}$ & $-I$ & 1.1436 & IV & Total Destruction of & The Evil Nature of & Animate and Inanimate Things \\
\hline I & $\mathbf{E}$ & I & 1.0973 & I & Total Commitment to & The Positive Uses of & Persons \\
\hline I & $-E$ & $-\mathbf{I}$ & 1.0973 & IV & Total Destruction of & The Abusive Uses of & Persons \\
\hline I & I & $\mathbf{E}$ & 1.0806 & I & Maximize Positive Effects of & The Sacred Nature of & Persons \\
\hline I & $-\mathbf{I}$ & $-\mathbf{E}$ & 1.0806 & IV & Minimize Negative Effects of & The Evil Nature of & Persons \\
\hline $\mathbf{S}$ & I & I & 1.0369 & I & Total Commitment to & The Sacred Nature of & Formal Systems \\
\hline $\mathbf{S}$ & $-\mathbf{I}$ & $-I$ & 1.0369 & IV & Total Destruction of & The Evil Nature of & Formal Systems \\
\hline $\mathbf{E}$ & $\mathbf{E}$ & I & 1.0042 & I & Total Commitment to & The Positive Uses of & Animate and Inanimate Things \\
\hline $\mathbf{E}$ & $-\mathbf{E}$ & $-\mathbf{I}$ & 1.0042 & IV & Total Destruction of & The Abusive Uses of & Animate and Inanimate Things \\
\hline I & $\mathbf{S}$ & I & 0.9747 & I & Total Commitment to & Rational Views of & Persons \\
\hline I & $-S$ & $-I$ & 0.9747 & IV & Total Destruction of & Irrational Views of & Persons \\
\hline $\mathbf{E}$ & I & $\mathbf{E}$ & 0.9719 & I & Maximize Positive Effects of & The Sacred Nature of & Animate and Inanimate Things \\
\hline $\mathbf{E}$ & $-I$ & $-\mathbf{E}$ & 0.9719 & IV & Maximize Negative Effects of & The Evil Nature of & Animate and Inanimate Things \\
\hline I & I & $\mathbf{S}$ & 0.9642 & I & Formal Acceptance of & The Sacred Nature of & Persons \\
\hline I & $-I$ & $-S$ & 0.9642 & IV & Formal Rejection of & The Evil Nature of & Persons \\
\hline I & $\mathbf{E}$ & $\mathbf{E}$ & 0.9210 & I & Maximize Positive Effects of & The Positive Uses of & Persons \\
\hline I & $-\mathbf{E}$ & $-\mathbf{E}$ & 0.9210 & IV & Minimize Negative Effects of & The Abusive Uses of & Persons \\
\hline $\mathbf{S}$ & $\mathbf{E}$ & I & 0.9085 & I & Total Commitment to & The Positive Uses of & Formal Systems \\
\hline $\mathbf{S}$ & $-\mathbf{E}$ & $-I$ & 0.9085 & IV & Total Destruction of & The Abusive Uses of & Formal Systems \\
\hline $\mathbf{E}$ & $\mathbf{S}$ & I & 0.8685 & I & Total Commitment to & Rational Views of & Animate and Inanimate Things \\
\hline $\mathbf{E}$ & $-S$ & $-I$ & 0.8685 & IV & Total Destruction of & Irrational Views of & Animate and Inanimate Things \\
\hline $\mathbf{S}$ & I & $\mathbf{E}$ & 0.8552 & I & Maximize Positive Effects of & The Sacred Nature of & Formal Systems \\
\hline
\end{tabular}


VAL VAL

\begin{tabular}{|c|c|c|c|c|c|c|c|}
\hline BASE & $\# 1$ & $\# 2$ & VECTOR & QUAD & VALUATION \# 2 & VALUATION \# 1 & BASE \\
\hline $\mathbf{S}$ & $-I$ & $-E$ & 0.8552 & IV & Minimize Negative Effects of & The Evil Nature of & Formal Systems \\
\hline $\mathbf{E}$ & I & $\mathbf{S}$ & 0.8427 & I & Formal Acceptance of & The Sacred Nature of & Animate and Inanimate Things \\
\hline $\mathbf{E}$ & $-\mathbf{I}$ & $-\mathbf{S}$ & 0.8427 & IV & Formal Rejection of & The Evil Nature of & Animate and Inanimate Things \\
\hline $\mathbf{E}$ & $\mathbf{E}$ & $\mathbf{E}$ & 0.8199 & I & Maximize Positive Effects of & The Positive Uses of & Animate and Inanimate Things \\
\hline $\mathbf{E}$ & $-E$ & $-E$ & 0.8199 & IV & Minimize Negative Effects of & The Abusive Uses of & Animate and Inanimate Things \\
\hline I & $\mathbf{S}$ & $\mathbf{E}$ & 0.7885 & I & Maximize Positive Effects of & Rational Views of & Persons \\
\hline I & $-\mathbf{S}$ & $-E$ & 0.7885 & IV & Minimize Negative Effects of & Irrational Views of & Persons \\
\hline I & $\mathbf{E}$ & $\mathbf{S}$ & 0.7850 & I & Formal Acceptance of & The Positive Uses of & Persons \\
\hline I & $-\mathbf{E}$ & $-\mathbf{S}$ & 0.7850 & IV & Formal Rejection of & The Abusive Uses of & Persons \\
\hline $\mathbf{S}$ & $\mathbf{S}$ & $\mathbf{I}$ & 0.7694 & I & Total Commitment to & Rational Views of & Formal Systems \\
\hline $\mathbf{S}$ & $-\mathbf{S}$ & $-\mathbf{I}$ & 0.7694 & IV & Total Destruction of & Irrational Views of & Formal Systems \\
\hline $\mathbf{S}$ & $\mathbf{E}$ & $\mathbf{E}$ & 0.7195 & I & Maximize Positive Effects of & The Positive Uses of & Formal Systems \\
\hline $\mathbf{S}$ & $-\mathbf{E}$ & $-E$ & 0.7195 & IV & Maximize Negative Effects of & The Abusive Uses of & Formal Systems \\
\hline $\mathbf{S}$ & I & $\mathbf{S}$ & 0.7094 & I & Formal Acceptance of & The Sacred Nature of & Formal Systems \\
\hline $\mathbf{S}$ & $-I$ & $-\mathbf{S}$ & 0.7094 & IV & Formal Rejection of & The Evil Nature of & Formal Systems \\
\hline $\mathbf{E}$ & $\mathbf{S}$ & $\mathbf{E}$ & 0.6793 & I & Maximize Positive Effects of & Rational Views of & Animate and Inanimate Things \\
\hline $\mathbf{E}$ & $-\mathbf{S}$ & $-E$ & 0.6793 & IV & Minimize Negative Effects of & Irrational Views of & Animate and Inanimate Things \\
\hline $\mathbf{E}$ & $\mathbf{E}$ & $\mathbf{S}$ & 0.6685 & I & Formal Acceptance of & The Positive Uses of & Animate and Inanimate Things \\
\hline $\mathbf{E}$ & $-\mathbf{E}$ & $-\mathbf{S}$ & 0.6685 & IV & Formal Rejection of & The Abusive Uses of & Animate and Inanimate Things \\
\hline I & $\mathbf{S}$ & $\mathbf{S}$ & 0.6318 & I & Formal Acceptance of & Rational Views of & Persons \\
\hline $\mathbf{I}$ & $-\mathbf{S}$ & $-\mathbf{S}$ & 0.6318 & IV & Formal Rejection of & Irrational Views of & Persons \\
\hline $\mathbf{S}$ & $\mathbf{S}$ & $\mathbf{E}$ & 0.5845 & I & Maximize Positive Effects of & Rational Views of & Formal Systems \\
\hline $\mathbf{S}$ & $-S$ & $-\mathbf{E}$ & 0.5845 & IV & Minimize Negative Effects of & Irrational Views of & Formal Systems \\
\hline $\mathbf{S}$ & $\mathbf{E}$ & $\mathbf{S}$ & 0.5510 & I & Formal Acceptance of & The Positive Uses of & Formal Systems \\
\hline $\mathbf{S}$ & $-\mathbf{E}$ & $-\mathbf{S}$ & 0.5510 & IV & Formal Rejection of & The Abusive Uses of & Formal Systems \\
\hline $\mathbf{E}$ & $\mathbf{S}$ & $\mathbf{S}$ & 0.5040 & I & Formal Acceptance of & Rational Views of & Animate and Inanimate Things \\
\hline $\mathbf{E}$ & $-\mathbf{S}$ & $-\mathbf{S}$ & 0.5040 & IV & Formal Rejection of & Irrational Views of & Animate and Inanimate Things \\
\hline $\mathbf{S}$ & $\mathbf{S}$ & $\mathbf{S}$ & 0.3976 & I & Formal Acceptance of & Rational Views of & Formal Systems \\
\hline
\end{tabular}


VAL VAL

\begin{tabular}{|c|c|c|c|c|c|c|c|}
\hline BASE & $\# 1$ & $\# 2$ & VECTOR & QUAD & VALUATION \# 2 & VALUATION \# 1 & BASE \\
\hline $\mathbf{S}$ & $-S$ & $-\mathbf{S}$ & 0.3976 & IV & Formal Rejection of & Irrational Views of & Formal Systems \\
\hline $\mathbf{S}$ & $-S$ & $\mathbf{S}$ & -0.3976 & III & Formal Acceptance of & Irrational Views of & Formal Systems \\
\hline $\mathbf{S}$ & $\mathbf{S}$ & $-\mathbf{S}$ & -0.3976 & II & Formal Rejection of & Rational Views of & Formal Systems \\
\hline $\mathbf{E}$ & $\mathbf{S}$ & $\mathbf{S}$ & -0.5040 & III & Formal Acceptance of & Irrational Views of & Animate and Inanimate Things \\
\hline $\mathbf{E}$ & $\mathbf{S}$ & $-\mathbf{S}$ & -0.5040 & II & Formal Rejection of & Rational Views of & Animate and Inanimate Things \\
\hline $\mathbf{S}$ & $-E$ & $\mathbf{S}$ & -0.5510 & III & Formal Acceptance of & The Abusive Uses of & Formal Systems \\
\hline $\mathbf{S}$ & $\mathbf{E}$ & $-\mathbf{S}$ & -0.5510 & III & Formal Rejection of & The Positive Uses of & Formal Systems \\
\hline $\mathbf{S}$ & $-S$ & $\mathbf{E}$ & -0.5845 & III & Maximize Negative Effects of & Irrational Views of & Formal Systems \\
\hline $\mathbf{S}$ & $\mathbf{S}$ & $-\mathbf{E}$ & -0.5845 & II & Minimize Positive Effects of & Rational Views of & Formal Systems \\
\hline I & $-\mathbf{S}$ & $\mathbf{S}$ & -0.6318 & III & Formal Acceptance of & Irrational Views of & Persons \\
\hline I & $\mathbf{S}$ & $-\mathbf{S}$ & -0.6318 & II & Formal Rejection of & Rational Views of & Persons \\
\hline $\mathbf{E}$ & $-\mathbf{E}$ & $\mathbf{S}$ & -0.6685 & III & Formal Acceptance of & The Abusive Uses of & Animate and Inanimate Things \\
\hline $\mathbf{E}$ & $\mathbf{E}$ & $-S$ & -0.6685 & II & Formal Rejection of & The Positive Uses of & Animate and Inanimate Things \\
\hline $\mathbf{E}$ & $-\mathbf{S}$ & $\mathbf{E}$ & -0.6793 & III & Maximize Negative Effects of & Irrational Views of & Animate and Inanimate Things \\
\hline $\mathbf{E}$ & $\mathbf{S}$ & $-\mathbf{E}$ & -0.6793 & II & Minimize Positive Effects of & Rational Views of & Animate and Inanimate Things \\
\hline $\mathbf{S}$ & $-\mathbf{I}$ & $\mathbf{S}$ & -0.7094 & III & Formal Acceptance of & The Evil Nature of & Formal Systems \\
\hline $\mathbf{S}$ & I & $-\mathbf{S}$ & -0.7094 & II & Formal Rejection of & The Sacred Nature of & Formal Systems \\
\hline $\mathbf{S}$ & $-\mathbf{E}$ & $\mathbf{E}$ & -0.7195 & III & Maximize Negative Effects of & The Abusive Uses of & Formal Systems \\
\hline $\mathbf{S}$ & $\mathbf{E}$ & $-\mathbf{E}$ & -0.7195 & II & Minimize Positive Effects of & The Positive Uses of & Formal Systems \\
\hline $\mathbf{S}$ & $\mathbf{S}$ & $-I$ & -0.7694 & II & Total Destruction of & Rational Views of & Formal Systems \\
\hline $\mathbf{S}$ & $-\mathbf{S}$ & I & -0.7694 & III & Total Commitment to & Irrational Views of & Formal Systems \\
\hline I & $-\mathbf{E}$ & $\mathbf{S}$ & -0.7850 & III & Formal Acceptance of & The Abusive Uses of & Persons \\
\hline $\mathbf{I}$ & $\mathbf{E}$ & $-\mathbf{S}$ & -0.7850 & II & Formal Rejection of & The Positive Uses of & Persons \\
\hline I & $-\mathbf{S}$ & $\mathbf{E}$ & -0.7885 & III & Maximize Negative Effects of & Irrational Views of & Persons \\
\hline I & $\mathbf{S}$ & $-\mathbf{E}$ & -0.7885 & II & Minimize Positive Effects of & Rational Views of & Persons \\
\hline $\mathbf{E}$ & $-\mathbf{E}$ & $\mathbf{E}$ & -0.8199 & III & Maximize Negative Effects of & The Abusive Uses of & Animate and Inanimate Things \\
\hline $\mathbf{E}$ & $\mathbf{E}$ & $-\mathbf{E}$ & -0.8199 & II & Minimize Positive Effects of & The Positive Uses of & Animate and Inanimate Things \\
\hline $\mathbf{E}$ & $-\mathbf{I}$ & $\mathbf{S}$ & -0.8427 & III & Formal Acceptance of & The Evil Nature of & Animate and Inanimate Things \\
\hline
\end{tabular}




\begin{tabular}{|c|c|c|c|c|c|c|c|}
\hline BASE & $\begin{array}{c}\text { VAL } \\
\# 1 \\
\end{array}$ & $\begin{array}{c}\text { VAL } \\
\# 2\end{array}$ & VECTOR & QUAD & VALUATION \# 2 & VALUATION \# 1 & BASE \\
\hline $\bar{E}$ & I & $-S$ & -0.8427 & II & Formal Rejection of & The Sacred Nature of & Animate and Inanimate Things \\
\hline $\mathbf{S}$ & $-I$ & $\mathbf{E}$ & -0.8552 & III & Maximize Negative Effects of & The Evil Nature of & Formal Systems \\
\hline $\mathbf{E}$ & $-S$ & I & -0.8685 & III & Total Commitment to & Irrational Views of & Animate and Inanimate Things \\
\hline $\mathbf{E}$ & $\mathbf{S}$ & $-I$ & -0.8685 & II & Total Destruction of & Rational Views of & Animate and Inanimate Things \\
\hline $\mathbf{S}$ & $-\mathbf{E}$ & I & -0.9085 & III & Total Commitment to & The Abusive Uses of & Formal Systems \\
\hline $\mathbf{S}$ & $\mathbf{E}$ & $-I$ & -0.9085 & II & Total Destruction of & The Positive Uses of & Formal Systems \\
\hline I & $-\mathbf{E}$ & $\mathbf{E}$ & -0.9210 & III & Maximize Negative Effects of & The Abusive Uses of & Persons \\
\hline I & $\mathbf{E}$ & $-\mathbf{E}$ & -0.9210 & II & Minimize Positive Effects of & The Positive Uses of & Persons \\
\hline I & $-I$ & $S$ & -0.9642 & III & Formal Acceptance of & The Evil Nature of & Persons \\
\hline I & I & $-S$ & -0.9642 & II & Formal Rejection of & The Sacred Nature of & Persons \\
\hline $\mathbf{E}$ & $-I$ & $\mathbf{E}$ & -0.9719 & III & Maximize Negative Effects of & The Evil Nature of & Animate and Inanimate Things \\
\hline $\mathbf{E}$ & $\mathbf{I}$ & $-\mathbf{E}$ & -0.9719 & II & Minimize Positive Effects of & The Sacred Nature of & Animate and Inanimate Things \\
\hline I & $-S$ & I & -0.9747 & III & Total Commitment to & Irrational Views of & Persons \\
\hline I & $\mathbf{S}$ & $-I$ & -0.9747 & II & Total Destruction of & Rational Views of & Persons \\
\hline $\mathbf{S}$ & $-I$ & $\mathbf{I}$ & -1.0369 & III & Total Commitment to & The Evil Nature of & Formal Systems \\
\hline $\mathbf{S}$ & I & $-I$ & -1.0369 & II & Total Destruction of & The Sacred Nature of & Formal Systems \\
\hline I & $-\mathbf{I}$ & $\mathbf{E}$ & -1.0806 & III & Maximize Negative Effects of & The Evil Nature of & Persons \\
\hline I & I & $-\mathbf{E}$ & -1.0806 & II & Minimize Positive Effects of & The Sacred Nature of & Persons \\
\hline $\mathbf{I}$ & $-\mathbf{E}$ & I & -1.0973 & III & Total Commitment to & The Abusive Uses of & Persons \\
\hline I & $\mathbf{E}$ & $-\mathbf{I}$ & -1.0973 & II & Total Destruction of & The Positive Uses of & Persons \\
\hline $\mathbf{E}$ & $-I$ & I & -1.1436 & III & Total Commitment to & The Evil Nature of & Animate and Inanimate Things \\
\hline $\mathbf{E}$ & $\mathbf{I}$ & $-I$ & -1.1436 & II & Total Destruction of & The Sacred Nature of & Animate and Inanimate Things \\
\hline I & $-I$ & $\mathbf{I}$ & -1.2423 & III & Total Commitment to & The Evil Nature of & Persons \\
\hline I & $\mathbf{I}$ & $-\mathbf{I}$ & -1.2423 & II & Total Destruction of & The Sacred Nature of & Persons \\
\hline
\end{tabular}




\section{B. Extrinsic Value and Partial Fulfillment of Intensions}

One of the most important aspects of Hartman's work pertains to partial fulfillment of analytic concepts by extrinsic values. Extrinsic values fulfill analytic intensions by degrees. Most of our value decisions are based on comparisons or preference. Formally this represents the partial or complete fulfillment of an analytic intension. Hartman's approach is based on examining numbers of properties. The more properties represented by competing extensions (of the same intension), the better the value.

It has been objected that merely counting properties is not sufficient. Some properties appear to be more important than others; their presence or absence is more serious. Even if we treat all properties as equal in importance, the problem of how to determine the relative value of two extensions of two different intensions would still remain. Hartman tells us that if an extension (a thing) has all five properties of a five predicate intension, then it is better than an extension having only four properties of the same intension. But how are we to compare the value of an extension having three properties of a five-propertied intension with an extension having three properties of a three-propertied intension?

Before giving a solution to this problem, let us review some features of Hartman's program. Specifically, just how do properties add value, and how are we able to make value classifications of "good" and "bad" from the arrangement of properties? The answer lies in Hartman's treatment of Pascal's Triangle.

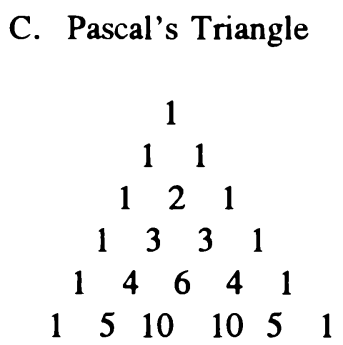

Pascal developed this remarkable triangle to demonstrate number generation and computing odds. In reality it is a binomial distribution. It also serves as an exposition of combinatorial sets. It is the combinatorial aspect that interests us. Hartman points out two important elements of the triangle. First, the triangle accounts for the number of predicates contained in an intension. This is done by counting the rows of the triangle. Each row 
represents a count of predicates.

Counting Predicates

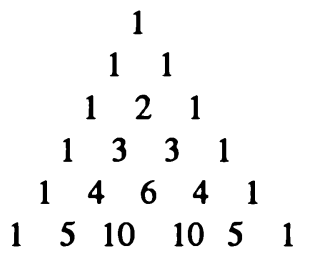

Number of predicates
on each row

0

1

2

3

4

5

Each column represents two things: First, it represents the number of combinations distinguishable for any given number of predicates. For example, row three "1 21 " (which is an intension with two predicates) has three value combinations: 1 is no-good, 2 are average, and 1 is good. In other words, the number of predicates in the intension directly determines the number of value combinations we can differentiate. Normally, we use five combinations: no-good, poor, average, fair, and good. In theory we could use many more, and the triangle gives a way of differentiating these combinations. Obviously, the more value categories we have at our disposal, the more precise the value differentiation; and this is determined by the number of predicates in the intension.

Second, each row also determines the number of sub-sets within each value category. For example, the row "1 21 " tells us that the category "no-good" has one subset, "average" has two subsets, and "good" has one subset. If we count the subsets in each row of the triangle we learn the following:

\begin{tabular}{|c|c|}
\hline Counting Subsets & $\begin{array}{l}\text { Number } \\
\text { per row }\end{array}$ \\
\hline 1 & 1 \\
\hline 11 & 2 \\
\hline $\begin{array}{lll}1 & 2 & 1\end{array}$ & 4 \\
\hline $\begin{array}{llll}1 & 3 & 3 & 1\end{array}$ & 8 \\
\hline $\begin{array}{lllll}1 & 4 & 6 & 4 & 1\end{array}$ & 16 \\
\hline $\begin{array}{llllll}1 & 5 & 10 & 10 & 5 & 1\end{array}$ & 32 \\
\hline
\end{tabular}

Each row multiplies by a factor of 2 the number of sub-sets in the previous 
row. This means:

1) The addition of one predicate in an intension doubles the amount of available information.

2) The addition of one predicate in an intension adds one new value category.

3) Each row carries all the information contained in every row above.

These three aspects of Hartman's value triangle are important in dealing with problems of partial concept fulfillment, which can be solved by the method of vectors. Following Hartman, let us think of a no-good extension as the fulfillment of definitional properties only and a complete lack of expositional properties. Now we can characterize value fulfillment as a scale going from the limits of systemic value (definitional properties only) to complete fulfillment of all expositional properties. This scale is sensitive to the number of predicates in the intension. The greater the number of predicates, the greater the amplitude of the intension:

Amplitude of Intension Wave:

Max Fulfillment of Properties $=1$ to 5: Normalized

$\begin{array}{lll}\text { Max Number of Predicates }=0 & \text { Normalized }=.1670 \\ \text { Max Number of Predicates }=1 & \text { Normalized }=.2336 \\ \text { Max Number of Predicates }=2 & \text { Normalized }=.3002 \\ \text { Max Number of Predicates }=3 & \text { Normalized }=.3668 \\ \text { Max Number of Predicates }=4 & \text { Normalized }=.4334 \\ \text { Max Number of Predicates }=5 & \text { Normalized }=.5000\end{array}$

Since an analytic intension can be partially or wholly fulfilled, we can also determine the amplitude of a partially fulfilled intension. Recall that each row of the triangle determines how many value categories are allowed, that is, how many ways there are to fulfill the intension. The greater the number of ways of fulfilling an intension, the greater the amplitude of the wave. Again, by referring to Pascal's Triangle, we can measure both the number of ways an intension can be fulfilled and the amplitude of the wave which fulfills the intension. 


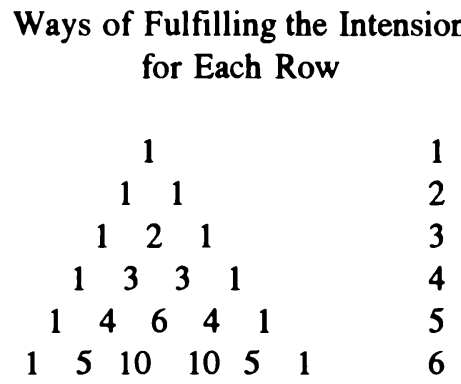

These ways of fulfillment can likewise be normalized:

Amplitude of Intension Fulfillment:

Fulfillment of Predicates $=1$ TO 5 Normalized

$\begin{array}{ll}\text { Max Number of Predicates }=0 & \text { Normalized }=.1670 \\ \text { Max Number of Predicates }=1 & \text { Normalized }=.2336 \\ \text { Max Number of Predicates }=2 & \text { Normalized }=.3002 \\ \text { Max Number of Predicates }=3 & \text { Normalized }=.3668 \\ \text { Max Number of Predicates }=4 & \text { Normalized }=.4334 \\ \text { Max Number of Predicates }=5 & \text { Normalized }=.5000\end{array}$

By summing the relation between the degree of fulfillment and the number of properties contained in the intension, we can determine the exact amplitude for each predicate and its degree of fulfillment, as follows:

Normalized Value Scale for Degrees of Extrinsic

Value Fulfillment per Number of Predicates in Intension

\begin{tabular}{cccc}
$\begin{array}{c}\text { NUMBER OF } \\
\text { PROPERTIES }\end{array}$ & $\begin{array}{c}\text { DEGREE OF } \\
\text { FULFILLMENT }\end{array}$ & AMPLITUDE \\
\hline 5 & 0.5000 & 0.5000 & 0.9239 \\
5 & 0.5000 & 0.4334 & 0.8495 \\
4 & 0.4334 & 0.4334 & 0.8008 \\
5 & 0.5000 & 0.3668 & 0.7756 \\
4 & 0.4334 & 0.3668 & 0.7265 \\
5 & 0.5000 & 0.3002 & 0.7033 \\
3 & 0.3668 & 0.3668 & 0.6778 \\
4 & 0.4334 & 0.3002 & 0.6528 \\
5 & 0.5000 & 0.2336 & 0.6352
\end{tabular}




$\begin{array}{llll}3 & 0.3668 & 0.3002 & 0.6034 \\ 4 & 0.4334 & 0.2336 & 0.5818 \\ 5 & 0.5000 & 0.1670 & 0.5751 \\ 2 & 0.3002 & 0.3002 & 0.5547 \\ 3 & 0.3668 & 0.2336 & 0.5302 \\ 4 & 0.4334 & 0.1670 & 0.5175 \\ 2 & 0.3002 & 0.2336 & 0.4804 \\ 3 & 0.3668 & 0.1670 & 0.4617 \\ 1 & 0.2336 & 0.2336 & 0.4316 \\ 2 & 0.3002 & 0.1670 & 0.4084 \\ 1 & 0.2336 & 0.1670 & 0.3575 \\ 0 & 0.1670 & 0.1670 & 0.3086\end{array}$

If we follow Hartman and represent these possibilities as sections of Pascal's Triangle, then there exits a clear order of relative value. The following representation of Pascal's Triangle assigns an ordinal rank to each position on the Triangle. " 1 " is that position which has the highest amplitude, and " 21 " has the lowest.

Value Priority
Number of

expositional properties:

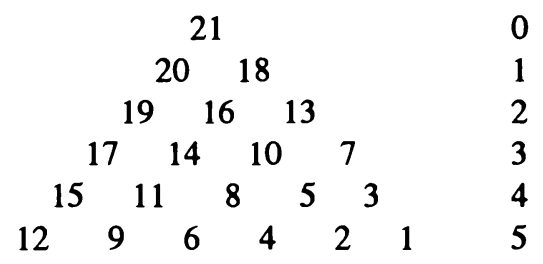

This table shows that a good three-propertied thing (ordinal rank $=7$ ) is better than an average four-propertied thing (ordinal rank $=8$ ); a fair three-propertied thing (ordinal rank $=10$ ) is better than a poor four-propertied thing (ordinal rank $=11$ ); and a fair four-propertied thing (ordinal rank $=5$ ) is better than a good three-propertied thing (ordinal rank $=7)$.

This is an interesting pattern. If we connect the next best elements on a diagonal in the triangle, and count the subsets in each diagonal row, then we replicate the Fibonacci Ratio, or the Golden Section. This pattern is as follows: 
D. Ordinal Ranking of Values

Ordinal Subsets

$$
\begin{aligned}
21 & =1 \\
20 & =1 \\
19,18 & =2 \\
17,16 & =3 \\
15,14,13 & =5 \\
12,11,10 & =8 \\
9,8,7 & =13^{*} \\
6,5 & =21^{*} \\
4,3 & =34^{*} \\
2 & =55^{*} \\
1 & =89^{*}
\end{aligned}
$$

(Note: * means that all the elements in the diagonal row are not shown.)

The Fibonacci pattern has shown itself to be one of the important ratios of how nature builds or develops itself through time. Growing organisms frequently display this pattern, and the Greeks were very keen on its embodiment of aesthetic proportion. It would indeed be significant if the Fibonacci Ratio is also a pattern of how meaning or relative value builds itself by the addition of predicates. It would define a pattern for how meaning adds to meaning. The vector analysis is similar to the Fibonacci pattern of how a certain number series adds.

\section{E. Comparing Ordinal Ranking of Values}

The above analysis is far too incomplete. From Hartman, we understand that the essence of valuation is property counting. By examining sets of predicates and their corresponding properties, we can determine overall value. This is deceptively simple, and with the aid of the algebra developed in this paper this can be seen. The particular properties a thing has are critical for determining its value. Each property has a different value per the level of differentiation. Various values per property and predicate permit the calculation of the relative value of individual elements within each subset.

Let us assume that a concept has five predicates: A, B, C, D, and E. If 
a thing has all five properties, this is better than having only four. However, it is not always so simple. In reality, these five properties represent subsets of property combinations. According to combinatorial algebra, five propertied things can be arranged in the following order:

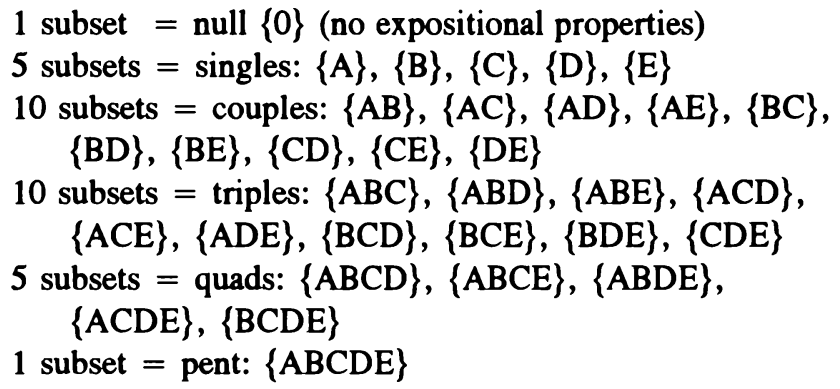

Each of these subsets has its own unique amplitude. The amplitude, as you may remember, is determined by adding the squares of the amplitudes of each element contained in the subset. This can be done as follows:

1) Determine the normalized amplitude of each predicate. From the table above, we know that:

$\begin{array}{cc}\text { PROPERTY } & \text { AMPLITUDE } \\ \text { NULL } & .1670 \\ \text { A } & .2336 \\ \text { B } & .3002 \\ \text { C } & .3668 \\ \text { D } & .4334 \\ \text { E } & .5000\end{array}$

2) Add the squares of each subset combination:

The following table is a complete listing of all subsets by their unique amplitudes: 
AMPLITUDES OF ALL COMBINATIONS OF SUBSETS FOR ONE TO FIVE PROPERTIED INTENSIONS

$$
-\{\mathrm{AB}\}=.0390 \quad\{\mathrm{~A}\}=.0540
$$

$-\{\mathrm{AB}\}=.0501$
$\{\mathrm{A}\}=.0545$
$\{\mathrm{AB}\}=.1446$
$\{B\}=.0901$

$$
-\{\mathrm{ABC}\}=.061
$$

$$
\begin{aligned}
& \{A\}=.0545 \\
& \{B\}=.0901 \\
& \{C\}=.1345
\end{aligned}
$$

$$
\begin{aligned}
& \{A B\}=.1446 \\
& \{A C\}=.1890 \\
& \{B C\}=.2246
\end{aligned}
$$

$-\{A B C D\}=.0723$

$$
\begin{aligned}
& \{A\}=.0545 \\
& \{B\}=.0901 \\
& \{C\}=.1345 \\
& \{D\}=.1878
\end{aligned}
$$

$\{A B\}=.1446$

$\{A C\}=.1890$

$\{\mathrm{AD}\}=.2424$

$\{\mathrm{BC}\}=.2246$

$\{\mathrm{BD}\}=.2779$

$\{C D\}=.3223$

$\begin{array}{ll}-\{A B C D E\}=.0835 & \{A\}=.0545 \\ & \{B\}=.0901 \\ & \{C\}=.1345 \\ & \{D\}=.1878 \\ & \{E\}=.2500\end{array}$
$\{\mathrm{ABC}\}=.2491$
$\{\mathrm{ABD}\}=.3324$
$\{A C D\}=.3768$
$\{\mathrm{BCD}\}=.4124$
$\{\mathrm{ABE}\}=.3946$
$\{\mathrm{ACE}\}=.4390$
$\{\mathrm{ADE}\}=.4923$
$\{B C E\}=.4746$
$\{\mathrm{BDE}\}=.5279$
$\{C D E\}=.5723$

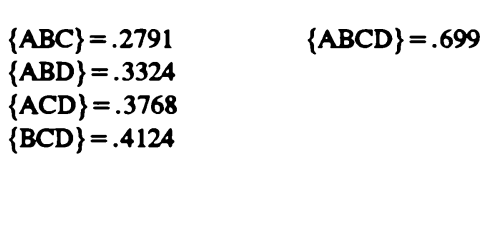

$\{\mathrm{ABC}\}=.2791$

$\{\mathrm{ABD}\}=.3324$

$\{\mathrm{ACD}\}=.3768$

$\{\mathrm{BCD}\}=.4124$

$\{\mathrm{ABCD}\}=.699$

$\{\mathrm{ABC}\}=.2791$

ABC $=.2791$

$\{\mathrm{ABCD}\}=.6992$

$\{\mathrm{ABCE}\}=.7614$

$\{\mathrm{ABDE}\}=.5824$

$\{\mathrm{ACDE}\}=.6268$

$\{\mathrm{BCDE}\}=.6624$ 
This chart is very revealing. In general, the category "fair four-propertied" (ordinal rank $=5$ ) is better than "poor-average five-propertied" (ordinal rank $=6$ ), but it is not true that every sub-set is better. For example, the set $\{D E\}$ of a five-propertied poor-average is, in fact, better than the set $\{B C D\}$ of four-propertied fair:

$$
\begin{aligned}
& \{\mathrm{DE}\}=.4378 \\
& \{\mathrm{BCD}\}=.4124
\end{aligned}
$$

Close inspection of the chart demonstrates that this is not an unusual occurrence. However, the average values for these sets of subsets agree with our original ordering of the sets.

Average value for "five-propertied poor-average" $=.2867$

Average value for "four-properties fair" $=.3501$

F. Average Value for all Sets of Subsets

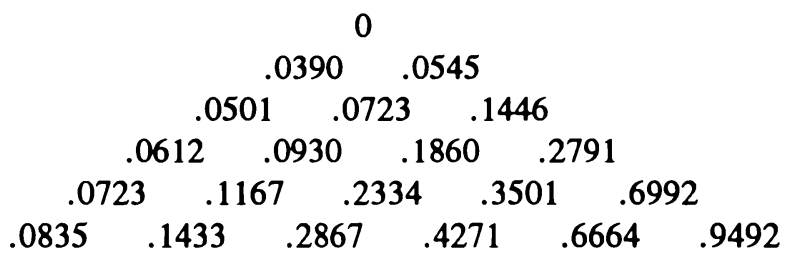

This table points out the great variety of valuations and provides a very nice confirmation of the important principle that blanket value judgements cannot be made without knowing the details. A very nice value principle may be important in general, but its importance may vary in different situations. This is consistent with the principles of quantum mechanics. When I speak of value priority in general, I only speak statistically, not absolutely. Individual variations cause very significant changes in actual value. Our general picture covers a host of variations.

\section{Applications}

The measurement of relative value must find its way to the real world. This is an awesome undertaking. What seems clear on a theoretical level quickly runs aground on the uneven details of the world. This is true for two fundamental reasons: First, the real world contains perturbations which 
defy measure. Newton's mechanics is a wonderful theoretical framework, and it has many exact applications; but if you want to predict exactly where a bullet fired from a rifle will land, then you are dealing with a level of detail over which measurement has scant control. It is not that we do not know that air currents, temperature, and moisture variations have an effect on the bullet's flight; the problem is that we cannot measure these effects with sufficient precision for accurate prediction. Second, when dealing with something as complex as values with a theoretical framework as new and untested as formal axiology, we are ill equipped to know which elements are relevant, and to what extent. So, applications are a quagmire. We must tread lightly, but let us try.

In his excellent book, Valuemetrics": The Science of Personal and Professional Ethics, Frank Forrest makes a most important step in applying formal axiology to real world situations. In what follows, I rely extensively on this ground breaking work in which Forrest utilizes Robert Hartman's transfinite algebra. For Hartman, value relations are either compositions or transpositions. Compositions are value combinations which are good, and transpositions are bad combinations. In applying Hartman's algebra, Forrest created a decision procedure which arrives at conclusions that demonstrate whether a certain situation is a composition or a transposition of value. Forrest's decision procedure requires a technical analysis of each situation. Although some may take exception, Forrest bravely takes on difficult issues such as abortion. ${ }^{6}$ That there may be objections should surprise no one. After all, this is a controversial issue. My purpose is to inquire if Forrest's conclusions agree with the quantum wave model.

There are three questions for comparison. First, do both methods agree on what constitutes compositions and transpositions? Second, do both methods agree on the value relations of "better than" and "worse than"? Finally, do both methods agree that transpositions are sometimes justifiable; and if so, under what conditions?

\section{A. Compositions and Transpositions}

Forrest utilizes a slightly different indicator for the cardinality of concepts than Robert Hartman. Hartman claimed that there are three type of concepts, formal, analytic, and singular, corresponding to three types of value. These concepts correspond to systemic, extrinsic and intrinsic value, respectively. The cardinality of each concept is as follows: 
Formal = Finite,

Analytic $=$ Infinite, and

Singular $=$ Nondenumerably Infinite.

Each type of concept or value can also be valued (composition) or disvalued (transposition); and their blending yields eighteen possible combinations. Forrest modifies Hartman's scheme in the following way:

Formal = Finite and definite or " $n$ ",

Analytic $=$ Finite and elastic or " $k$ ", and

Singular $=$ Nondenumerably Infinite or " $A^{n}[k]$.

Forrest correctly characterizes the eighteen combinations of composition and transposition as eight distinct cardinalities. These cardinalities are as follows:

$$
\begin{aligned}
& A_{1} \wedge_{1}, k^{\wedge}, n^{\wedge}=A_{2} \\
& A_{1}{ }^{k}, A_{1}{ }^{n}=A_{1} \\
& \mathrm{k}^{\mathrm{k}}, \mathrm{n}^{\mathrm{k}}, \mathrm{k}^{\mathrm{n}}=\mathrm{k} \\
& \mathrm{n}^{\mathrm{n}}=\mathrm{n} \\
& n^{-n}=1 / n \\
& k^{-k}, n^{-k}, k^{-n}=1 / k \\
& A_{1}^{-k}, A_{1}^{-n}=1 / A_{1} \\
& A_{1}{ }^{-A_{1}}, k^{-A_{1}}, n^{-A_{1}}=1 / A_{2}
\end{aligned}
$$

Forrest's rank order for the eighteen combinations of compositions and transpositions yields only eight distinct and different cardinalities. The quantum wave method, on the contrary, yields eighteen distinct rankings, as follows: 


\begin{tabular}{cccc}
$\begin{array}{c}\text { HARTMAN } \\
\text { RANK }\end{array}$ & BASE & VAL\#1 & VECTOR \\
\hline 1 & I & I & 0.9239 \\
2 & E & I & 0.7965 \\
4 & I & E & 0.7353 \\
3 & S & I & 0.6542 \\
6 & E & E & 0.6097 \\
5 & I & S & 0.5695 \\
7 & S & E & 0.4790 \\
8 & E & S & 0.4249 \\
9 & S & S & 0.2957 \\
10 & S & $-S$ & -0.2957 \\
11 & E & $-S$ & -0.4249 \\
12 & S & $-E$ & -0.4790 \\
14 & I & $-S$ & -0.5695 \\
13 & E & $-E$ & -0.6097 \\
16 & S & $-I$ & -0.6542 \\
15 & I & $-E$ & -0.7353 \\
17 & E & $-I$ & -0.7965 \\
18 & I & $-I$ & -0.9239
\end{tabular}

Except for this difference, all combinations that Forrest recognizes as compositions and as transpositions agree with the quantum wave method.

\section{B. Better Than and Worse Than}

In formal axiology, compositions are better than transpositions; but axiology must provide a method for deciding on the relative goodness or badness of particular value relations. Forrest's analysis distinguishes eight cardinalities based on the eighteen binary value combinations. Four of these cardinalities are compositions, and four are transpositions. Ranking the eight cardinalities from best to worst yields the following scale:

1) $\quad A_{1} \wedge_{1}, k A_{1}, n A_{1}=A_{2}$

2) $A_{1}^{k}, A_{1}^{n}=A_{1}$

3) $k^{k}, n^{k}, k^{n}=k$

4) $n^{n}=n$ 
5) $n^{-n}=1 / n$

6) $\mathrm{k}^{-\mathrm{k}}, \mathrm{n}^{-\mathrm{k}}, \mathrm{k}^{-\mathrm{n}}=1 / \mathrm{k}$

7) $A_{1}^{-k}, A_{1}^{-n}=1 / A_{1}$

8) $\quad A_{1} \cdot A_{1}, k^{-A_{1}}, n^{-A_{1}}=1 / A_{2}$

In this scale,

$A_{2}$ is better than $A_{1}$;

$A_{1}$ is better than $k$;

$\mathrm{k}$ is better than $\mathrm{n}$;

$\mathrm{n}$ is better than $1 / \mathrm{n}$;

$1 / \mathrm{n}$ is better than $1 / \mathrm{k}$;

$1 / \mathrm{k}$ is better than $1 / A_{1}$; and

$1 / A_{1}$ is better than $1 / A_{2}$.

The quantum wave method offers at least eighteen, not just eight, different relations of better than and worse than. The vector length is the measure of value. The larger the vector, the better the value. The quantum wave method is not limited to eighteen binary value combinations. As earlier demonstrated, it can include distinct values and levels of value other than the primary intrinsic, extrinsic, and systemic values.

\section{Using Transpositions to Maintain or Create Value}

Ethics is sticky stuff. We are familiar with the dilemma of fifteen persons trying to occupy a ten-person life boat, or telling a lie to protect or save life. There are a variety of responses to these situations. Some hold the view that it is justifiable to commit a wrong act if the act results in a greater good. Others say that bad is never justifiable, no matter how good the intended outcome. Forrest clearly takes the view that doing wrong, committing transpositions of value, is justifiable in certain cases. Transpositions can create or maintain compositions of value, and these are justifiable. Forrest offers an interesting analysis of these cases. According to my understanding, Forrest employs the following principle:

A transposition is justifiable if and only if 1 ) the two situations are causally related by necessary and sufficient conditions; and 2) the 
cardinality of the transposition is equal to or less than the cardinality of a consequent transposition (except cardinalities which are $A_{1}$ ).

This principle first tells us that a transposition is justifiable if it is the only way to maintain or bring about a composition. Second, it tells us that the cardinality of the transposition must not be larger than the composition. That is, it may be acceptable to do wrong to achieve a higher good, but it is not acceptable to do a greater wrong to achieve a lesser good. Forrest offers the following example. ${ }^{7}$

"an illegal rule that protects people's welfare"

Forest contends that the use of the transposition, "illegal rule," is justifiable to protect the higher good of "people's welfare." He demonstrates this in the following way:

1) "illegal rule" has cardinality of $1 / n$; while

2) "people's welfare" has cardinality of $A_{1}$.

Therefore, the illegal rule is bad, but not as bad as the good in people's welfare; it is, therefore, justifiable.

What would the quantum wave model say about this example? To arrive at the answer we only need to sum the respective vectors. If the resultant sum is positive, then it is justifiable, if negative then it is not justifiable.

1) "illegal rule" has vector $=-0.2957$; while

2) "people's welfare" has vector $=0.7965$.

Adding 1) and 2) yields a positive number; and if 1) is the only viable way to protect 2), then it is justifiable.

In another example, Forrest considers whether it is justifiable to kill insects to protect crops. ${ }^{8}$ Forrest analyses this situation in the following way:

1) "killing insects" has cardinality $=1 / \mathrm{k}$; while

2) "ruining crops" has cardinality $=1 / \mathrm{k}$.

Here the two cardinalities are equal; and, on Forrest's analysis, 1) is justifiable.

On the quantum wave model we find that the relevant vectors of both 1) and 2) are -0.6097; both are equally bad. However, as noted above in the section dealing with partial fulfillment of intensions, the relevant details and properties involved are critically important to measure the vector. If we go no further than the analysis provided by Forrest, then we can only say that the two vectors are equal. Additional information may very well demonstrate that one vector is longer than another, and thus the issue is resolved. For example, if we add to the above description the fact that protecting crops is important to prevent malnutrition in people, then the 
property loss for persons would certainly be much greater than the loss of some insects. But as long as the two vectors are exactly equal, I see no justification for concluding that the consequent justifies the antecedent.

This is a critical difference between the two models. For Forrest, using a transposition to create or protect value of equal cardinality is justifiable, but for the quantum wave model it is not. If the two vectors are truly equal, then there is no justification to choose one over the other. The two situations are value-neutral. Moreover, in Forrest's algebra, only eight distinct cardinalities cover a multitude of value situations. This algebra does not provide enough resolution to deal adequately with the value landscape. In the quantum wave model, not only are there eighteen distinct value types (as opposed to eight); but, as was demonstrated above, inside each of the eighteen value types, there is infinite room for constructing vectors of varying length to account for diverse configurations of both the number and the relative importance of properties.

Forrest also considers cases where using a transposition to prohibit other transpositions is not justified. We shall review two cases:

The first example is: "lying to conceal illegal evidence." Here

1) "lying" is cardinality $=1 / \mathrm{k}$; while

2) "illegal evidence" is cardinality $=1 / n$

Since $1 / \mathrm{k}$ is smaller than $1 / \mathrm{n}$, then lying in this case is not justified.

The quantum wave model gives a similar result:

1) "lying" has vector of -0.6097 ; while

2) "illegal evidence" has vector of -.02957.

Another example is: "harming a person in performing a medical experiment;" 10

1) "harming a person" has cardinality $=1 / A_{1 ;}$ while

2) "medical experiment" has cardinality $=k$.

According to the quantum wave model:

1) "harming a person" has vector $=-0.7353$; while

2) "medical experiment" has vector $=0.6097$.

These results agree with Forrest's conclusions.

In another case, Forrest considers "lying to prevent harm to an innocent person." "He finds this transposition justifiable because

1) "lying" has cardinality $=1 / \mathrm{k}$; while

2) "harm innocent person" has cardinality $=1 / A_{1}$.

According to the quantum wave model:

1) "lying" has vector $=-0.6097$; while

2) "harm innocent person" has vector $=-0.7353$.

This confirms Forrest's results. 
Forrest also considers capital punishment. He argues that capital punishment for murder is justifiable. ${ }^{12}$ He presents this case as follows:

1) "execution" has cardinality $=1 / A_{1}$; while

2) "murder" has cardinality $=1 / A_{2}$

The quantum wave model indicates that

1) "execution" has vector $=-0.7353$; while

2) "murder" has vector $=-0.9239$.

Again, Forrest's results are confirmed. However, in this case, there are alternative ways to describe the situation. Execution of a murderer is an act of killing. It is not clear that execution is merely the extrinsic disvaluation of a person. Perhaps it is an intrinsic disvaluation of a person; and, if it is, execution has the same cardinality as murder. Perhaps Jesus would agree. If the two vectors are the same, the quantum wave model does not support capital punishment unless additional details are relevant.

First, for the quantum wave model, the subset of properties of a murderer are likely different from and less valuable than those of an innocent victim. Both are persons; and for Hartmanean algebra, both have the same cardinality. However, the quantum wave vectors for both persons are likely unequal. We might argue that a murderer's set of properties is not as rich as the innocent victim's set of properties; therefore, the murderer's vector is less than the innocent victim's. On this basis, killing a murderer as the only way to prevent the killing of an innocent victim would be justifiable.

Second, on the quantum wave model, killing one person is not as bad as killing two or three persons. Wave vectors add; additional acts of evil increase overall evil. It is important to note this because it is not true for Hartmanean algebra. So, on the quantum wave model, execution is justified to prevent murder or additional murders only if this is the only alternative. It would be justified to kill Hitler; but this does not mean that execution is the best course of action. If incarceration could achieve the same result, then execution would not be justified. The quantum wave model analyses this alternative in the following way:

1) "incarceration" has vector $=-0.7353$;

2) "execution of murderer" has max vector $=-0.9293$; while

3) "murder one innocent person" has min vector $=-0.9239$; and

4) "murder two innocent persons" has min vector $=-1.8586$, etc. (Quantum waves add.)

Therefore, killing to prevent murder is justifiable if and only if 1) incarceration or interdiction is not possible, and 2) the vector of the murderer is less than the vector of the victim. Would it be justifiable to kill a murderer to protect another murderer? 
I conclude with two general points. First, the quantum wave model confirms and agrees with Forrest's construction of Hartmanean Algebra in almost all cases. Second, the quantum wave model does not confirm Forrest's algebra in two areas. First, the quantum wave model offers a more detailed analysis of value relations. This allows for greater comparative analysis both of diversity of value types and particular differences within each value type. Second, the quantum wave model does not recognize that a transposition is justifiable merely because its vector equals the composition's vector.

\section{Conclusion}

In this essay, I try to lay the groundwork for the future development of Scientific Axiology. Building on what is good about Hartman's work and overcoming the shortcomings is not an easy task. Specifically, I have tried to relate the two-fold nature of the concept with the two-fold nature of the electron. Like an electron, a concept has a particle (extensional) and a wave (intensional) component. Thus, the intension or meaning of a concept can be analyzed via the wave amplitudes and vectors of quantum algebra. I have tried to show that quantum logic is plausible for value logic.

I do not intend to say that I have proven some dynamic new connection between quantum theory and axiology, but I wish to explore this area. The problems in Hartman's axiology are formidable. However, if Formal Axiology is to become the science we wish it to be, these problems must be solved. I can only hope that my work will be viewed as an attempt to further our understanding, and I trust that it will receive critical attention. Only through scrutiny and criticism can we move forward.

Finally, every principle and formula utilized in this paper can be expressed as a function in Fuzzy Logic. I direct attention to an important new book by Bart Kosko: Neural Networks and Fuzzy Systems. ${ }^{13}$ Fuzzy Logic is actual value logic, especially for the gradations of value found in the extrinsic value domain. I stress the importance of Fuzzy Logic for Hartman's value theory, and I invite investigation of this most important new field. 


\section{ENDNOTES}

1. See: Frank G. Forrest, Valuemetrics": The Science of Personal and Professional Ethics, (Atlanta - Amsterdam: Editions Rodopi, 1994), p. 79.

2. P. Y. A. Gunter, "Hartman: Three Criticisms," The Journal of Value Inquiry, 7:2 (Summer 1973), p. 137.

3. Robert S. Brumbaugh, "Changes of Value Order and Choices in Time," in Value and Valuation: Axiological Studies in Honor of Robert S. Hartman, ed. John W. Davis, (Knoxville, Tenn.: The University of Tennessee Press, 1972), p. 51.

4. Mark A. Moore, "Hartman's Value Theory: Formal Models," in Rem B. Edwards and John W. Davis, eds., Forms of Value and Valuation: Theory and Applications, (Lanham, Md.: University Press of America, 1991), pp. 171-192.

5. Roger Penrose, The Emperor's New Mind: Concerning Computers, Minds, and the Laws of Physics, (New York: Penguin Books, 1989), Ch. 10.

6. Forrest, Valuemetrics": The Science of Personal and Professional Ethics, pp. 145-152.

7. Ibid., p. 92.

8. Ibid., p. 93.

9. Ibid., p. 94.

10. Ibid., p. 95.

11. Ibid., p. 98.

12. Ibid., p. 99.

13. Bart Kosko, Neural Networks and Fuzzy Systems: A Dynamical Approach to Machine Intelligence, (Englewood Cliffs: Prentice Hall, 1992). 